\title{
Experiences and Coping Strategies of Children From Child-Headed Households in Swaziland
}

\author{
S'lungile K. Thwala \\ Correspondence: S'lungile K. Thwala, Department of Educational Foundations and Management, University of \\ Swaziland.
}

Received: March 6, 2018

doi:10.11114/jets.v6i7.3393

\author{
Accepted: May 15, $2018 \quad$ Online Published: June 27, 2018
}

URL: https://doi.org/10.11114/jets.v6i7.3393

\begin{abstract}
This study investigated the experiences and coping strategies of adolescent girl learners from child-headed families in the Shiselweni region of Swaziland. Forty (40) girls whose ages ranged from 13-18 years were participants in the study and were selected through purposive sampling in five selected rural schools. Data were collected on the experiences and coping strategies of adolescent girl learners through focus group discussions and individual interviews. The data were thematically analysed. The findings suggest that these girls experience lack of food security, poverty and strained extended family relations. The girls have also shown resilience despite their adversities which they indicated have been achieved through family unity, prayer and church support as coping strategies.
\end{abstract}

Keywords: adolescent, adversities, child-headed families, community, experiences, resilience, Swaziland

\section{Introduction}

Globally, the family structure is constantly changing and knowledge about families and their significance vary across the different nations (Leatham, 2006). The traditional family structure which used to include parents and their children in the same household is slowly diminishing. One of the attributing factors to this scenario which is prominent is the impact of HIV and AIDS pandemic which has left many children orphaned and most of them are still school going. According to Moletsane (2004), this situation has hit hard the African society, resulting in child-headed households $(\mathrm{CHH})$ as a new family structure.

The definition of CHH may be contentious as the term 'child' may mean different things to different people (MacLellan, 2005; Smart 2003; UNAIDS 2006). According to MacLellan (2005), the most acceptable definition of a child refers to a person under the age of 18 years; however, one should be cautious about the use of a quantitative number in differentiating a child from an adult. According to Mogotlane, Chauke, Human., Van Rensburg, Van der Wal, and De Beer, (2008:35), 'a household is a unit that traditionally accommodates a family'. Usually a household is characterised by several aspects, such as, culture, religion, legal frameworks and social dynamics of particular communities (UNICEF, 2009). Murphy, Harvey and Silvestre (2005) view a household as an economic unit where members eat from the same pot or sleep under the same roof. The construct of a household is problematic due to the fluid nature of its changing membership. The composition and structure of households may change as a result of death, disease, crime, migrant labour, unemployment, conflicts, war, separation and desertion which may contribute to CHH (MacLellan, 2005; Smart 2003). Ayieko (2004), however, points out that there is a distinction between a family and a household. In the former the people are related, but in the latter they may not necessarily be related even if they live together (Bower, 2005; Germann 2005).

Child-headed household is relatively a new phenomenon in Africa as encounters of child-headed families in Sub-Saharan Africa was first reported in Uganda in 1980, Tanzania, Zambia and Zimbabwe in 1991 and 1992 respectively (Moletsane, 2004). This phenomenon can be attributed to rapid increase in numbers of parental deaths, poverty and HIV/AIDS pandemic being the most prominent causes. It is estimated that one hundred and fifty million persons affected by the HIV/AIDS pandemic live in the African continent (Leatham, 2006; Ankrah, 1993; Foster, Levine, \& Williamson, 2005).

It is alleged that the HIV/AIDS scourge has also left about forty-two million orphans in Sub-Saharan Africa, whose care and socialization are in serious jeopardy due to the diminished economic capacity of traditional care structures and weakened national economies. HIV/AIDS has destroyed the social and economic infrastructure on which poverty eradication and development in Africa depends (Human Development report, 2004). Pharaoh (2004) notes that 
economic impact in several countries income in orphan households has been found to be 20-30 percent lower than in non-orphaned households. Other studies (Foster, Levine, \& Williamson, 2005; Subbarao \& Coury, 2004) have suggested that food consumption may drop by as much as 41 percent orphan households. Asset selling to pay for health care, loss of income by breadwinners and funeral costs may deplete all household, as well as savings.

The African society has for a long time, been popular of its unique family structure known as the extended family which used to take care of orphaned children. However, considering the current economic climate facing the Sub-Saharan Africa that has extended to families and community members, such has undermined the unique extended family structure which used to characterize the African society hence it is rapidly disappearing (Nkomo, 2006). Swaziland is no exception to this scenario as it is also highly affected by the HIV/AIDS pandemic hence the emergence of the child-headed households in 2002. The extended family structure which used to control, determine and safeguard all actions of its members is also disappearing because of the economic crises facing the country. The extended families used to ensure that the orphaned children were evenly distributed amongst the family members who assumed full responsibility of the orphaned children as though they were their own biological parents. This arrangement ensured that orphaned children were provided with food, shelter and clothing (Bellano, Dawes, Hildebrand \& Lewis, 2013).

Child-headed households are at risk of having to cope without parental care or regular income and are located in areas where services are poor. In addition, this vulnerable group has to deal with emotional strain and is more likely to be abused and exploited. The children heading or coming from these families are part of the education community and some of them are adolescents who have been forced to assume the adult responsibilities because of the HIV/AIDS pandemic (Abdool \& Abdool, 2008). Hence, the objective of the study was to determine the lived experiences of children from child-headed households and their coping strategies. The research question that informed the study was; what are the lived experiences of children from child-headed households and how do the children cope with life under their circumstances?

\section{Literature Review}

An elaborate interrogation of both national and international literature on $\mathrm{CHH}$, presenting experiences and coping strategies of child headed learners was done which led to the identification of several challenges that are experienced by children living in such households. Some of these challenges are: increased responsibility of a nurse and care for sick family members (Evans \& Becker, 2009; Skovdal, Ogutu, Aoro, \& Campbell, 2009); the difficulty of dealing with the stigma of family members being sick or dead due to HIV/AIDS (Campbell et al. 2012); the lack of grief support (Pillay, 2012); shortage of resources (Seckinelgin 2007); increased risk of starvation and malnutrition (Madhavan \& Townsend, 2007); increased school absenteeism and withdrawal (Cluver, Operario, Lane, \& Kganakga, 2012); poor school performance (Guo, Li \& Sherr, 2012); inadequate access to medical care (Skovdal \& Daniel, 2012) and the sexual exploitation of girls (Pillay, 2012).

The challenges experienced by children in $\mathrm{CHH}$ clearly reflect their social disempowerment and devastating experiences of poverty, which are further exacerbated by the lack of adequate social support from their families and communities (Van Dijk \& Van Driel, 2012). While much focus has been given to the challenges of CHH, (Lethale \& Pillay, 2013) posit that one should also be cognisant of the fact that there are several children in such households who display strong resilience. Cheney (2010) argues that viewing children from CHH as vulnerable may unintentionally create a sense of dependency and entitlement for relief aid to address the arising pathology and also may lead to undermining and minimising the plight of $\mathrm{CHH}$. Thus a further interrogation in this view is inevitable

In order to enhance the comprehension of this concept $\mathrm{CHH}$, the authors chose three different models of Resilience Theoretical Framework which they believed would add value in understanding of CHH as a concept. Baylis (2012) views resilience as a universal human capacity that enables a person, group or community to deal with adversities by preventing, minimizing, overcoming and even being transformed by these adversities. It stipulates that an individual is naturally endowed with the ability to cope with adversity; however this capacity needs nurturing and support from within the environment so that resilience can be attained. On the contrary, the Van Breda Model

(2001) depicts a shift from deficits to individual strength, competencies and capacities which are described as critical steps in comprehending resilience within the individual, family and larger social environment

The third model postulates that children, families and communities have protective capacities or processes which enable them to cope in their challenging circumstances. The current study was greatly informed by this third model in trying to ascertain the lived experiences of the adolescent girl learners from child headed families as they enunciated their coping strategies under their conditions. The protective capacities or processes encompass the experiences and mechanisms that permit positive adaptation irrespective of the adversities. These include internal personal strengths, interpersonal resources or skills and external support (Gunnestad, 2003)

Taking the above theories into consideration, the authors utilised the Resilience Model because it explained how some 
adolescents exposed to highly stressful situations and conditions did not sustain developmental damages as some children exposed to such difficult situations used them as a ladder to grow stronger. It was again viewed as a useful weapon for survival of adolescents from child-headed households. They navigated the uncharted ground which was without parental guidance, love, direction and discipline. These girls have endured what is termed "the learn as you go type of experiential learning curve" (Sibanda, 2015:8). They grew in poverty and had to survive under such conditions, as others argued that they sometimes went to bed without a meal. These adolescents overcame hurdles such as losing parents, attempting to administer discipline to younger siblings, taunted, deserted by extended family and abused by their respective communities.

The source of rebound and recovery for the adolescents was attributed to the protective factors; inner capacity and more so resources such as strong sense of self, good social skills, sense of purpose in life, self-control, individual factors such as genetics, personality, ethnicity, and social factors such as socio-economic background, supportive caregivers and geographical proximity to others, social and community support such as support from family, friends, community and schools (Germann, 2005).

\section{Methodology}

\subsection{Research Design}

The study adopted a phenomenological research design which employed qualitative methods to explore the experiences and coping strategies of adolescent girl learners from child-headed families in the Shiselweni region of Swaziland. A phenomenological approach allows participants to give meaning to their own experiences and to understand and interpret this meaning (Leedy \& Ormrod, 2010). The design was appropriate for this study because it sought to explore experiences, perceptions and coping strategies of adolescent girl learners who come from child-headed families.

\subsubsection{Participants and Setting}

Participants were forty adolescent girls; age range 13-18 from five rural high schools in the Shiselweni region of Swaziland. Both schools and learners were selected using criterion purposive sampling. The five participating schools were purposefully selected through the help of the Regional administrator and the learners selected with the help of the schools' administration and the community health motivators. According to McMillan and Schumacher (2014), in criterion sampling the researcher picks cases that meet the set criteria for the study, which in this case were schools with child headed adolescent girl learners who were between 13 and 18 years (see table 1 below).

\subsection{Data Collection Methods and Procedure}

The learners participated in focus group discussions and individual interviews to report on their experiences and coping strategies in the child-headed families. Forty (40) adolescents participated in the focus group discussions and ten (10) learners identified to be having rich cases during the focus group discussions also participated in individual interviews. The focus group discussion lasted for forty-five (45) minutes to one hour thirty (1hr 30) minutes. The individual interviews lasted between 30 to 45 minutes. A tape recorder was used to capture the participants' responses and notes were also recorded for relevancy.

\subsection{Trustworthiness}

Measures to ensure trustworthiness were utilised in this study, namely credibility, transferability, dependability and conformability. Credibility was ensured through member checks with participants for accuracy of responses checking for any discrepancies of meaning. The use of verbatim quotes from the data collected allows for transferability of the study. The tape recordings were accurately recorded and were replayed for the same participants of the study. Each of the participants was asked questions to confirm their responses from the data.

\subsection{Ethical Clearance}

Ethical clearance was obtained from the Ministry of Education to conduct the research. Since the participants were all minors less than eighteen (18) years of age, informed consent was sought from the school principals. Participants were given a consent form to sign, in which they agreed to be interviewed and have their verbatim statements quoted. There was assurance for confidentiality and anonymity which was enhanced by the use of pseudonyms. The schools in question, where the research was undertaken were also kept anonymous. Participants were also notified from the onset that they were at liberty to withdraw at any given point from the study and they were not going to be questioned about their withdrawal.

\subsection{Data Analysis}

Data were thematically analyzed by scrutinizing for commonalities using the approach by Brikci and Green (2007). According to Brikci and Green (2007), this approach entails six steps which are: familiarization with the data, generating of tentative codes, elucidation of themes, review of themes, delineation of themes and producing a written report. Data analyses took place at the same time as data collection and questions raised during transcription were used to shape the questions for the next interviews. 


\section{Results}

Themes and subthemes which emerged from the thematic analysis are outlined in table 1 below. The themes are: lack of food security, poverty, strained extended family relations and coping strategies. All quotations in support of the themes are given without correction of grammatical errors. The following table shows themes that emerged from the study:

Table 1. Themes and categories from the data analysis

\begin{tabular}{lc}
\hline Themes & Categories \\
\hline Lack of food security & No meals for days \\
& Malnutrition \\
& Insufficient food supply \\
& No decent clothing \\
& No money \\
& No electricity \\
& Inferiority complex \\
& No balanced diet \\
& Deprived of parents' property \\
& Harassment \\
Strained extended family relations & Unity in the families \\
& Church support \\
Coping strategies & Neighbours support \\
& responsible for the well-being of their families \\
& perform domestic work \\
Sense of Independence & fend for themselves \\
domestic work
\end{tabular}

Information from table 1 shows that $\mathrm{CHH}$ face numerous challenges such as food insecurity, stigmatization and strained relationships from extended family members.

\subsection{Food Insecurity}

The participants both in the focus group discussions and individual interviews revealed that they experience lack of food security in their various homesteads. The participants stated that they would go for consecutive days without food in their different homesteads and when schools are opened, they get their only meals for the day at school through the school feeding scheme. One participant stated as follows:

In my home we sometimes go on empty stomachs for consecutive days because there is nothing to eat and my grandmother would advise us to drink water assuring us that we will not die; I usually get my first and only meal at school if schools are operational. In the case schools are closed, I report to the neighbours who then offer mealie meal to the family and I sometimes exchange domestic labour to the neighborhood in-order to get money to buy food for the family (participant \# 4, 14yrs, school B).

A large number of the participants revealed that they do not have decent clothing and as such rely on second hand clothing from sympathetic friends and neighbours. This can be attributed to the extent of the poverty the participants endure. They posited that they wish to have new clothing like their peers especially stylish clothing but their conditions deprive them of such hence they rely on second hand clothing one participant stated as follows:

It has been a long time since I last dressed up in new clothing. My friends offered me clothing and
this pains me the most and at the same time rouses inferiority complex in me when I'm with my
friends in church or attending weekend classes (participant \#6, 17yrs, F2, school D).

Most of the learners also reported that due to poverty they could not even afford to secure sanitary pads every month hence they were forced to use unhealthy means during their menstruation periods. For instance one participant stated as follows:

I do not afford sanitary pads on a monthly basis because my sister who often assists me would tell me that she does not have money; I'm then forced to wear numerous under-wears i.e. bundle them up as pads during my monthly periods (Primrose, 14yrs, F2, school D).

Most of the participants in school D revealed that the administration makes them pay an initial fee of five hundred and fifty (E550) emalangeni which they said they failed to secure. This resulted, in their end of year results being withheld by the school administration. The participants revealed that they eventually got the results after desperately presenting their different cases to the school administration. They however stated that such an experience exposed their vulnerability and subjected them to a lot of stress. One participant stated as follow: 
I'm currently repeating form II because I failed to secure money for the top up fee so I do not know whether I passed or failed in 2015 as my third term result was withheld by the school administration (participant \# 4, 17yrs, F2, school D).

\subsection{Strained Extended Family Relations}

Most of the participants' responses reflected that they had strained relationships with their extended family due to the property they grabbed from them after the death of their parents. One participant related how they were deprived of their parents' homestead the participant had this to say;

I was surprised to find my grandmother and some of my aunts occupying my parents' house when I came back from visiting one of my aunts (mother's sister) during one of the school holidays. We were forced to pack all our clothing and went back to Aunt to report what had happened to us (Glen, 16yrs, F2, school C).

\subsection{Coping Strategies}

Most participants (28) indicated positive coping strategies in their situation. They attributed their strength to their siblings; church, prayer and neighbours' support which they claimed helped them in spiritual healing. The aforementioned acted as protective factors for these children hence the adaptation to their situation despite the adversities they have gone through. A majority of the participants maintained that family unit has given them the courage to face life without wavering. The participant is quoted having said:

My sister promised to take my mother's role in my life, she encouraged me to report to her all my problems and she portrayed love to me on a daily basis this made me to grow strong as I felt her love despite that she could not afford to buy me all the things I wanted (participant \#4 15,14yrs, F1, school B).

Most of the learners revealed that believing in the Christian doctrine that God caters for orphans, have helped in creating courage and resilience in their lives.

One participant remarked;

I greatly believe in God the fact that there is someone I trust who is supreme keeps me going (participant \# 3, F2, school A)

Participants said that the spiritual support they received from the church kept them going as one participant remarked;

"The church has encouraged me to stay strong in prayer" and another remarked that the fact that they were not discriminated against in society made them to face each day with the determination that they would make it.

In the event I encounter challenges in life they said I must be free to report. My neighbours are also accommodative to me together with my other siblings hence if we do not have food at home we get food from them (participant \# 4, 17yrs, F4, school C).

Again other participants indicated that prayer was another pillar of strength for them, arguing that in the event they happen to have memories of their parents or are faced with difficulties in their present life, they would pray. They stated that after praying, they would feel relieved from whatever was troubling them. One participant had this to say:

If it happens that I'm accused of something that I have not done where I stay and be scolded for no apparent reason. I would pray after the prayer I would begin to feel better (Glen16yrs, F2, school C).

Most of the participants confirmed that the church has contributed a lot towards their resilience. They stated that from the church they have learnt the principles of life and moral values. Again, the church is said to have shown their spiritual support to the children by also visiting their families and have encouraged them to report all their problems to them. One participant was quoted having said:

The church is a usual visitor in my home and it has urged us to freely report to them the problems we encounter as a family for spiritual support (Girlee, 15, F3).

Another concurred;

My family neighbours who belong to my church are caring for my family; now and again they pay us a visit where they would also advise us on life issues. I remember during the ploughing season, they joined us when weeding our family fields (Girlee, 15yrs, F2).

\subsection{Sense of Independency}

The participants, during the focus group discussions, indicated that they have developed a sense of independency hence 
they are responsible for the well-being of their families and are having a clear focus with life. Most of the participants indicated that they contribute towards generating food for their respective families they stated that on weekends and when schools are closed most of them perform domestic work in the neighbourhood which include; weeding fields, harvesting fields, clean yards and wash their neighbours' clothes.

One participant stated as follows:

When schools are closed and on weekends I do domestic work for neighbours, I use this money to buy myself clothings, cosmetics and sanitary pads (participant \#4, 16yrs, F1, school D).

The participants again revealed that most of them sell sweets or snacks in their respective schools and from the profit they buy cosmetics and sanitary pads.

Another participant had this to say:

I also contribute towards food in the family and purchasing of my cosmetics as I perform domestic work in the neighbourhood when schools are closed or on weekends ( participant \# 6, 15 yrs, F1, school B)

The findings also revealed that the leaners despite the hardships they face in their different homestead have a dream of gaining professional employment in the near future so as to come out of poverty and further support their other siblings especially those with younger siblings.

One participant had this to say:

I believe that one day I will finish school and start working and support my siblings, it is a matter of three years( participant \# 4, 17 yrs, F4, school A)

\section{Discussions}

The findings reflect that the children lack food security. The fact that the learners would sometimes not have food to eat in their homes, deprive them of one of their basic needs which must be met in-order to have a healthy life. Going to school on empty stomach would sometimes compromise their concentration in class.

The findings of the current study concurs with the findings of a study conducted by Gorongo and Moyo (2013) in Zimbabwe whereby children from child headed families revealed that they did not have adequate food supply hence, they would sometimes go to bed without having eaten anything. Another study conducted by Save the Children in conjunction with the United Nations Education fund (UNICEF) in the country in 2009 in the Shiselweni and Lubombo region in selected constituencies also concurred with the current study's findings that the children are faced with unreliable sources of income as a result they seldom get enough food resulting in some of them going to school on empty stomachs.

The findings also reflect that because of high poverty levels, the learners failed to afford decent clothing and new school uniform. The learners depended on second hand clothing and this compromised their self-esteem because they perceived themselves inferior to their peers when attending classes on weekends. Material depravation also resulted in socio-emotional deprivation. According to Nyakutse (2006), socio-emotional deprivation could harm social identity development. Self-esteem which is important for social identity (Carr, 2004; Hewitt, 2002) underpins social wellbeing. Walsh, (2006) concurs that a strong social identity is important for emotional, spiritual and intellectual maturity

The finding on the clothing issue concurs with findings derived by Gorongo and Moyo (2013) in a study conducted in Zimbabwe where learners reported that they lack decent clothing which impacted negatively on them when they are with their peers especially during school functions.

Reflecting on Gunnestad (2003) and Van Breda's (2001) models of resilience one would contend that the children had developed resilience by picking role models from different people in their communities who were viewed as protective factors in their lives. According to the third model of the Resilience, the availability of competent adults in the society who serve as role models to children is important towards molding positive attitudes and adaptive coping to these children. It is said that positive role models are instrumental in helping children to develop strong moral values (Pharaoh, Richter, \& Killian, 2004).

The findings revealed that the participants experience strained relationships with their extended families especially the paternal families. Some of them revealed that their paternal families deprived them of their parents' properties which included money, furniture and homes. One participant narrated how she and her brother came back from school holidays only to discover that they had no place to stay as their home was occupied by her grandmother and aunts who claimed the ownership. Such attests to the argument by Khupiso (2007) that children from child-headed families are vulnerable to economic exploitation as sometimes they are chased away from their homes by relatives who claim to have inherited the home from the deceased parents. This form of harassment is not ideal for the children because they 
will grow up knowing that people are subjects for harassment. The children in the above circumstances are exposed to a negative emotional environment because they lack support from their relatives and this hinder their development into persons with good personal qualities

The extended family is believed to be having a crucial role towards consoling and comforting a child as well as giving a normal structure to the child's life after parental death. It is argued that if the child is accorded such, it is easier for him/her to regain control of her life and this result in the reduction of stress for the child and can make coping easier after the traumatic experience (Thwala, 2013).

According to Thwala (2013) in pre-colonial Africa there was an extended family system, whereby the status of a child was not defined by the marital status of parents, the child was not the responsibility of a particular parent for livelihood but; the welfare and upbringing of the child was a concern of the entire community. However, with urbanization emerged nuclear families which dictate that children be entirely dependent on their biological parents for livelihood and this have distorted the extended family support.

In establishing how the children cope with life, the findings of the study depicted that the learners are coping with life despite the adversities. The main strength of the learners is family unity. The children experience the sense of belonging and feeling of being part of their families under the custody of their elder siblings. This is in line with the model of resilience by (Gunnestad, 2003; Van Breda, 2001). Hence, the results of this study showed that the children enjoyed the support from their elder siblings in their different homesteads. Again the role of resilience and protective factors has featured in the findings in the sense that the participants used religious philosophy as a resource in their lives which acts as positive influence and were able to make a distinction between right and wrong behavior. Almost all the participants cited that they believe in prayer and going to church as the source of strength despite the adversities. One would commend the church for providing spiritual and moral support to the participants.

The findings have also indicated that some of the children have just accepted their situation because of the fact that their parents died whilst they were still too young so they do not have a clear picture of them. Another stated that her mother who was the last to die was sick for almost four (4) years hence she saw death coming towards her mother hence; she accepted the fact that she will eventually die. This shows that the participants apply the internal personal strength as a resource for resilience. Under this resource it is stated that some children are born with the innate internal strength that enables them to cope better in life. These children understand and express a wide range of their emotions in a socially appropriate manner and these make them to be more resilient as they are able to gain mastery and control over adversities (Van Breda, 2010). Again, the fact that these children have their elder siblings to express their emotions has helped to propel their coping under their situation.

\section{Implications}

The findings of this study have indeed revealed that adolescent girls from child headed homesteads have different experiences that were expressed through food insecurity, strained relationship with their extended family members, psychological problems and a sense of independency. These experiences necessitate that the children are afforded appropriate support to enable them to cope with difficulties. The Ministry of Education and Training need to consider introducing guidance and counselling department in all the schools of the country and the personnel employed in this office must have relevant qualifications so that they can offer quality service to the learners.

The decline of community or clan 'ownership' of children in the face of an increased trend to nuclear families has exacerbated the problems that child headed families face and has increased the requirement for urgent and creative interventions to help them survive and achieve adulthood as well-adjusted and secure individuals. The deputy prime minister's office which is responsible for the orphaned and vulnerable children needs to consider providing support to adolescent girls learners as the adolescents revealed that they lack basic needs for survival. There is also a need to revive the Parent Teachers' Association in all the schools in the country and these associations need to take the issue of children from child-headed families as their priority in their agenda, as these children need parental love and guidance. The findings of the study suggest the need for churches to play a pivotal role as the adolescent girls use prayer as one of their coping strategies in their lives.

\section{Conclusions}

Adolescents from child-headed families endure a poor quality of life; evidence to this is the fact that they experience lack of sufficient food supply and cannot afford decent clothing. This is attributed to the poverty they are facing in their respective homesteads. Despite the poor quality of life the adolescents endure; they have shown remarkable resilience and resourcefulness. They have demonstrated strategies which have helped them to recover from the adversities they have used family unity, church, religious belief, prayer and neighbours support as their protective factors. The participants rather than allowing themselves to be passive victims of unsatisfactory care arrangement, they have taken major steps to help shape and change their experiences. 


\section{References}

Abdool, S., \& Abdool, K. Q. (2008). The Impact of HIV/AIDS on Community: HIV/AIDS in South Africa. Cape Town: Cambridge University Press.

Ankrah, (1993). From Single to Child-headed Households: The case of children orphaned by aids in Kisimu \& Siaya Districts: University of Illinois. Department of International programmes \& studies.

Ayieko, M. A. (2004). From single parents to child-headed households: The case of children orphaned by AIDS in Kisumu and Siaya districts, Kenya.

Balyis, P. (2002). Promoting resilience: A review of literature. Paper prepared for the Alberta Mental Board, Children's mental health, 2002, http://www.amhb.ab.ca/chmh/resources/page.cfm?pg=Promoting\%20Resilience $\% 20$. Retrieved 22.02.2018

Bellano, L., Dawes, B., Hildebrand, C., \& Lewis, J. (2013). Swaziland: Pensions and Child headed households: African Grandmothers Tribunal-Seeking Justice at the Frontlines of the AIDS crisis

Bower, C. (2005). South Africa: The case for child-headed households. Early Childhood Matters, December, 45-49.

Brikci, N., \& Green, J. (2007). A guide to using qualitative research methodology. London, Health Services Research Unit: London School of Hygiene and Tropical Medicine

Campbell, C., Skovdal, M., Mupambireyi, Z., Madanhire, C., Robertson, L., Nyamukapa, C. A., \& Gregson, S. (2012). Can AIDS stigma be reduced to poverty stigma? Exploring Zimbabwean children's representations of poverty and AIDS, Child: Care, Health and Development, 38(5), 732-742. https://doi.org/10.1111/j.1365-2214.2011.01311.x

Carr, A. (2004). Positive psychology: The science of happiness and human strengths. New York: Brunner-Routledge.

Cheney, K. E. (2010). Expanding vulnerability, dwindling resources: Implications for orphaned futures in Uganda, Childhood in Africa, 2(1), 8-15.

Cluver, L., Operario, D., Lane, T., \& Kganakga, M., (2012). "I can't go to school and leave her in so much pain": Educational shortfalls among adolescent "young carers" in the South African AIDS epidemic, Journal of Adolescent Research, 27(5), 581-605. https://doi.org/10.1177/0743558411417868

Evans, R., \& Becker, S., (2009). Children caring for parents with HIV and AIDS: Global issues and policy responses, Policy Press, Bristol, UK.

Foster, G., Levine, C., \& Williamson, J. (2005). A generation at risk: The global impact of HIV/AIDS on orphans and vulnerable children. Cambridge: Cambridge University Press. https://doi.org/10.1017/CBO9781139164436

Germann, S. E. (2005). An exploratory study of quality of life and coping strategies of orphans living in child headed households in high HIV/AIDS prevalent city of Bulawayo, Zimbabwe, Unpublished doctoral thesis. University of South Africa, Pretoria.

Gorongo, P., \& Moyo, N. (2013). The lived experiences of adolescent secondary school learners from child-headed households: A case study of Cranborne Boys High School, Harare, Zimbabwe.

Gunnestad, A. (2003). Resilience - A new approach to children at risk in the Southern African situation. (1). Trondheim, Norway: Network for Preschool Teacher Training and Preschool Development in Southern Africa.

Guo, Y., Li, X., \& Sherr, L. (2012). The impact of HIV/AIDS on children's educational outcome: A critical review of global literature, AIDS Care, 24(8), 993-1012. https://doi.org/10.1080/09540121.2012.668170

Hewitt, J. P. (2002). The social construction of self-esteem. In C. R. Snyder., \& S. J. Lopez (eds.), Handbook of positive psychology (pp. 135-147). New York: Oxford University Press.

Khupiso, V. (2007). October 28). Thugs hit aids orphans. Sunday Times Metro.

Leatham, P. (2006). The lived experiences of adolescent learners from child-headed families in the Northern Free States. Unpublished Masters' Thesis. Johannesburg: University of Johannesburg.

Leedy, P. D., \& Ormrod, J. (2010). Practical research: planning \& design ( ${ }^{\text {th }}$ ed). New Jersey: Pearson Education International.

Lethale, P., \& Pillay, J. (2013). Resilience against all odds: A positive psychology perspective of adolescent-headed families, Africa Education Review, 10(3), 579-594. https://doi.org/10.1080/18146627.2013.853550

MacLellan, M. (2005). Child headed households: Dilemmas of definition and livelihood rights, African Studies Centre, Coventry University.

Madhavan, S., \& Townsend, N. (2007). The social context of children's nutritional status in rural South Africa, 
Scandinavian Journal of Public Health, 3(69), 107. https://doi.org/10.1080/14034950701355700

Mogotlane, S. M., Chauke, M. E., Human, S. P., van Rensburg, G. H., van der Wal, D. M., \& de Beer, F. (2008). A situational analysis of child-headed households in South Africa. Report on research conducted by the University of South Africa, Unisa, Pretoria.

Moletsane, M. (2004). Challenges faced by both learners orphaned by AIDS and their educators in South African schools. Pretoria: University of Pretoria.

Murphy, L. L., Harvey, P., \& Silvestre, E. (2005). How do we know about the impact of AIDS on food and livelihood insecurity? A review of empirical research from rural Sub-Saharan Africa, Human Organization, 64(3), 265-275. https://doi.org/10.17730/humo.64.3.bqmn8meqxlmr5a83

Nkomo, N. (2006). The experiences of children carrying responsibilities for child-headed households as a result of parents death due to HIV/AIDS. Masters' thesis. Pretoria: University of South Africa.

Nyakutse, G. (2006). Communicating with children in crisis. Paper presented at the 8th network conference for preschool teacher training and development in South Africa, Manzini, Swaziland.

Pharaoh, R., Richter, L., \& Killian, B. (2004). A generation at risk? HIV/AIDS, Vulnerable children and security in Southern Africa. Institute for Security Studies.

Pharoah, R. (2004). A generation at risk? HIV vulnerable children and security in South Africa. Pretoria: Institution for Security Studies.

Pillay, J. (2012). Experiences of learners from child-headed households in a vulnerable school that makes a difference: Lessons for school psychologists, School Psychology International, 33(1), 3-21. https://doi.org/10.1177/0143034311409994

Seckinelgin, H. (2007). The international politics of HIV/AIDS: Global disease, local pain, Routledge, London

Sibanda, J. (2015). Factors influencing primary health care services utilization by children living in child headed families in a rural community of Swaziland. University of South Africa, Health studies.

Skovdal, M., \& Daniel, M. (2012).Resilience through participation and coping-enabling social environments: The case of HIV-affected children in Sub-Saharan Africa, African Journal of AIDS Research, 11(3), 153-164. http://dx.doi.org/ 10.2989/16085906. 2012.734975

Skovdal, M., Ogutu, V., Aoro, C., \& Campbell, C. (2009). Young carers as social actors: coping strategies of children caring for ailing or ageing guardians in western Kenya, Social Science and Medicine, 69(4), 587-595. http://dx.doi.org/10.1016/j. socscimed.2009.06.016

Smart, R. (2003). Policies for orphans and vulnerable children: A framework for moving ahead, Policy Project, USAID, Washington, DC.

Subbarao, K., \& Coury, D. (2004). Reaching out to Africa's orphans - A framework for publication. Washington, DC: The World Bank. https://doi.org/10.1596/0-8213-5857-X

Thwala, S. K. (2013). The role of culture in psychosocial development of orphans and vulnerable children, International Journal of Adolescence and Youth, 18(2), 105-121. https://doi.org/10.1080/02673843.2012.665169

UNAIDS (2006). Report on the global AIDS epidemic, Chapter 4. UNAIDS.

UNICEF (2009). Convention on the rights of children, UNICEF.

Van Breda, A. D. ( 2010). The phenomenon and concerns of child-headed households in Africa. Sozialarbeit des Südens, (3), 259-279.

Van Breda, A. D. (2001). Resilience Theory: A literature review. South African Military Health Services, Military Psychological institute, Social Work Research \& Development.

Van Dijk, D., \& Van Driel, F. (2009). Supporting child-headed households in South Africa: Whose best interests?, Journal of Southern African Studies, 35(4), 915-927. https://doi.org/10.1080/03057070903313251

Walsh, F. (2006). Strengthening family resilience. ( $2^{\text {nd }}$ ed.).New York: Guilford Press.

\section{Copyrights}

Copyright for this article is retained by the author(s), with first publication rights granted to the journal.

This is an open-access article distributed under the terms and conditions of the Creative Commons Attribution license which permits unrestricted use, distribution, and reproduction in any medium, provided the original work is properly cited. 